\section{Physician's global assessment is often useful in SLE, but not always: the case of clinical remission}

We read with interest the paper by Aranow et al ${ }^{1}$ where physician's global assessment (PGA) displayed excellent inter-rater reliability, which could rely on the inclusion of highly selected lupus experts, as stated by the authors themselves. Indeed, in previous studies, PGA showed a high intra-rater and inter-rater variability, ${ }^{23}$ consistently with PGA being a subjective measure.

The high inter-rater reliability observed by the authors is surprising considering that the timeframe for assessing disease activity significantly varied among respondents: $36.7 \%$ scored PGA over the previous $7-10$ days, $36.7 \%$ over the previous month, the remainder over shorter or longer periods of time. Additionally, in almost one-third of respondents, lupus damage was considered when scoring PGA.

Notably, the authors suggest that PGA should be scored after considering laboratory results, owing to a better correlation with systemic lupus erythematosus (SLE) disease activity index-2000 (SLEDAI-2K) of postlaboratory versus prelaboratory PGA.

The finding that laboratory results, including serology, influence PGA performance raises some considerations.

In Aranow's study, each serological abnormality was associated with a median delta PGA prelab versus postlab of $\geq 0.3,{ }^{1}$ that is, the threshold for a clinically meaningful change in PGA. As PGA is incorporated in composite outcome measures including SLEresponder index and BILAG-based Combined Lupus Assessment (BICLA), the numerically significant impact of serology might reduce response rate in clinical trials, overpowering any clinical improvement.

Finally, a relevant question deals with the inclusion of PGA in a definition of clinical remission, which is a state of clinical quiescence, irrespective of serology. ${ }^{45}$ How could PGA fit in this definition? In Aranow's study, abnormal serology alone determined a median PGA increase of 0.54 for low C4, 0.41 for elevated anti-dsDNA antibody levels, 0.41 for low C3. ${ }^{1}$ The DORIS definition of clinical remission includes a cut-off of $<0.5$ for PGA; therefore, one can argue that, by affecting PGA, abnormal serology could prevent the achievement of clinical remission definition or could lead to a loss of clinical remission status.

We recently tested in a multicentre cohort of 646 patients with SLE, followed up for five consecutive years, the performance of the items included in DORIS definitions, that is, PGA $<0.5$ (scored prior to reviewing complement and anti-DNA antibody test), clinical (c)SLEDAI- $2 \mathrm{~K}=0$ and prednisone $\leq 0.5 \mathrm{mg} /$ day, alone or in combination, in defining remission and predicting damage. ${ }^{6}$ We found that adding PGA $<0.5$ to cSLEDAI- $2 \mathrm{~K}=0$ did not increase the performance of cSLEDAI-2K against damage progression while resulting in loss of remission in a relevant proportion of patients.

More recently, in the same cohort, we found that PGA $\geq 0.5$ despite cSLEDAI-2K=0, which was observed in 195 patients, was associated with (1) nonspecific patient-reported symptoms $(157 / 195,80.5 \%)$ and (2) objectifiable clinical manifestations not included in SLEDAI-2K or not reaching the threshold to be scored in SLEDAI-2K (38/195, 19.5\%) (table 1).

As remission should identify patients with better outcome, we compared damage progression, measured by SLICC/ACR Damage Index, between patients in clinical remission according to cSLEDAI-2K $=0$ plus PGA $<0.5$ and those in conditions (1) or
Table 1 Symptoms and manifestations which led to $P G A \geq 0.5$ * despite cSLEDAI-2K=0 in a multicentre cohort of 646 patients with lupus

\begin{tabular}{|c|c|}
\hline Patients with PGA $\geq 0.5$ and cSLEDAI $-2 \mathrm{~K}=0$ & $195 / 646(30.2 \%)$ \\
\hline $\begin{array}{l}\text { 1. Patients with subjective findings without objectifiable } \\
\text { clinical manifestations likely due to SLE (condition 1) }\end{array}$ & $157 / 195(80.5 \%)$ \\
\hline Musculoskeletal domain & 98 \\
\hline Arthromyalgias & 95 \\
\hline Low back pain & 10 \\
\hline Morning stiffness & 8 \\
\hline Asthenia/fatigue & 66 \\
\hline Paraesthesia & 1 \\
\hline Finger stings & 1 \\
\hline Shortness of breath & 1 \\
\hline Nausea & 1 \\
\hline Burning mouth syndrome & 1 \\
\hline Ocular pain & 1 \\
\hline Dermatitis/urticaria & 1 \\
\hline $\begin{array}{l}\text { Multiple symptoms (arthromyalgias, asthenia, anxiety, panic } \\
\text { attack, hallucinations, demoralisation, sleepiness, confusion, } \\
\text { headache, memory deficit, dizziness, insomnia, vision loss, } \\
\text { low-grade fever, chronic cough, paraesthesia, finger stings, } \\
\text { chronic pharyngodynia, fast heartbeat, chronic itch, influenza } \\
\text { syndrome, hand/foot ulcers, constipation, vaginosis and/or } \\
\text { effluvium canillorum) }\end{array}$ & 25 \\
\hline
\end{tabular}

\begin{tabular}{ll}
$\begin{array}{l}\text { 2. Patients with objectifiable clinical manifestations likely due } \\
\text { to SLE (condition 2) }\end{array}$ & $38 / 195$ (19.5\%) \\
$\begin{array}{l}\text { Haematological involvement (i.e., lymphopenia, haemolytic } \\
\text { anaemia) }\end{array}$ & 10 \\
$\begin{array}{l}\text { Monoarthritis } \\
\text { Proteinuriał }\end{array}$ & 10 \\
\hline $\begin{array}{l}\text { Recurrent infections leading to withdrawal/reduction of } \\
\text { immunosuppressive therapy }\end{array}$ & 6 \\
\hline Chilblain lupus erythematosus & 2 \\
\hline Lower limbs sensory neuropathy & 1 \\
\hline Lymphadenopathy & 1 \\
\hline Hand pitting scars & 1 \\
\hline Impaired diffusing capacity of the lung for carbon monoxide & 1 \\
\hline Tachyarrhythmia & 1 \\
\hline Venous thrombosis in secondary antiphospholipid syndrome & 1 \\
\hline Hepatic-pancreatic enzyme increase & 1 \\
\hline Depression & 1 \\
\hline
\end{tabular}

*PGA was scored prior to reviewing complement and anti-DNA antibody test. tnot included in SLEDAI-2K.

¥Proteinuria $\leq 0.5 \mathrm{gr} / \mathrm{day}$.

CSLEDAI-2K, clinical SLE disease activity index-2000; PGA, physician's global assessment; SLE, systemic lupus erythematosus.

(2). No difference was observed in the proportion of patients accruing new damage during follow-up (cSLEDAI- $2 \mathrm{~K}=0$ and PGA<0.5: 33.3\%, condition (1): $26.8 \%$, condition (2): $36.8 \%$, $\mathrm{p}=0.256$ ), suggesting that the symptoms/manifestations captured by PGA but not scored by cSLEDAI-2K could not affect damage. Thus, the inclusion of PGA in a definition of remission prevents the achievement of this status in a relevant proportion of patients without identifying a subgroup with a better prognosis.

Altogether, our data and those by Aranow et al highlight that inclusion of PGA in a definition of clinical remission gives relevance to serology, patient-reported symptoms and clinical manifestations unable to impair disease outcome while overshadowing the benefits of achieving remission according to less subjective disease activity indices. 


\section{Margherita Zen, Francesca Saccon, Mariele Gatto, Andrea Doria}

Department of Medicine DIMED, Division of Rheumatology, University of Padua, Padova, Italy

Correspondence to Professor Andrea Doria, Department of Medicine DIMED, Division of Rheumatology, University of Padua, Padova 35122, Italy; adoria@unipd.it

Contributors $\mathrm{MZ}$ contributed in conceiving the letter, analysed data and drafted the manuscript. FS collected and analysed data. MG analysed data and revised the letter. AD conceived and revised the letter. All the authors approved the final version.

Funding The authors have not declared a specific grant for this research from any funding agency in the public, commercial or not-for-profit sectors.

Competing interests None declared.

Patient and public involvement Patients and/or the public were not involved in the design, or conduct, or reporting, or dissemination plans of this research.

Patient consent for publication Not required.

Provenance and peer review Not commissioned; internally peer reviewed.

(C) Author(s) (or their employer(s)) 2020. No commercial re-use. See rights and permissions. Published by BMJ.

\section{D) Check for updates}

To cite Zen M, Saccon F, Gatto M, et al. Ann Rheum Dis Epub ahead of print: [please include Day Month Year]. doi:10.1136/annrheumdis-2020-217611

Received 14 April 2020

Accepted 18 April 2020

\section{Linked}

- http://dx.doi.org/10.1136/annrheumdis-2020-217687

Ann Rheum Dis 2020;0:1-2. doi:10.1136/annrheumdis-2020-217611

\section{ORCID iD}

Andrea Doria http://orcid.org/0000-0003-0548-4983

\section{REFERENCES}

1 Aranow C, Askanase A, Oon S, et al. Laboratory investigation results influence physician's global assessment (PGA) of disease activity in SLE. Ann Rheum Dis 2020:annrheumdis-2019-216753.

2 Isenberg DA, Allen E, Farewell V, et al. An assessment of disease flare in patients with systemic lupus erythematosus: a comparison of BILAG 2004 and the flare version of SELENA. Ann Rheum Dis 2011;70:54-9.

3 Wollaston SJ, Farewell VT, Isenberg DA, et al. Defining response in systemic lupus erythematosus: a study by the systemic lupus international collaborating clinics group. $J$ Rheumatol 2004;31:2390-4.

4 Zen M, laccarino L, Gatto M, et al. Prolonged remission in Caucasian patients with SLE: prevalence and outcomes. Ann Rheum Dis 2015;74:2117-22.

5 van Vollenhoven R, Voskuyl A, Bertsias G, et al. A framework for remission in SLE: consensus findings from a large international Task force on definitions of remission in SLE (DORIS). Ann Rheum Dis 2017:76:554-61.

6 Saccon F, Zen M, Gatto M, et al. Remission in systemic lupus erythematosus: testing different definitions in a large multicentre cohort. Ann Rheum Dis 2020. doi:10.1136/ annrheumdis-2020-217070. [Epub ahead of print: $22 \mathrm{Apr} 2020$ ]. 